\title{
Analysis of the Impact of Mechanical Deformation on Strawberries Harvested from the Farm
}

\author{
Dr. Joy Iong Zong Chen, \\ Professor, Department of Electrical Engineering, \\ Da-Yeh University, \\ Taiwan. \\ Email id: jchen@mail.dyu.edu.tw \\ Lu-Tsou Yeh, \\ Department of Electrical Engineering, \\ Da-Yeh University, \\ Taiwan.
}

\begin{abstract}
When fresh strawberry fruit are mechanically handled, they are very susceptible to damage. In order to stop this macro-damage of the fruit caused due to external factors and in order to determine reason for textural failure mechanics and evolution of the tissue, they are characterized using the un/loading test at various speeds of compression. Structural failure, local plastic and elastic are the three stages of deformation observed from the strawberry fruit. Based on the compression speed and direction of loading, determine the cut-off points and this is further validated with the use of visual change of colour in the fruit. Based on the observation, it was found that both compression speed as well as loading direction determined absorbed energy as well as peak force while damaged mass percentage was due to only loading direction. Observed results are recorded and the average failure energy, strain and stress of the fruit's inner tissue are evaluated to determine the effect of external mechanical damage.
\end{abstract}

Keywords: Smart farming, strawberry fruit farming, deformation of vegetation, textural failure;

\section{Introduction}

One of the crucial factors of the human diet is the intake of fresh strawberry. A survey of the strawberry production showed that over 14.6 billion dollars worth strawberry has been sold within a period of 10 years accounting for an annual production of 7 million tons. Hence the quality of the strawberry also plays a crucial role. From the consumer point of view, the texture of the fruit or vegetable is an important quality attribute [1]. These fruits are highly susceptible to damage because of repetitive mechanical handling leading to the perishing of the product at a quicker rate. Strawberry that is produced in the farm is transmitted to the destination location However over the course of this process losses occur from the time it is gathered from the farm and begins to accumulate over the course of time in the supply change. Moreover, since the fruits are mechanically handled, it will further accelerate the deterioration process. Moreover fruits which have slight signs of damage are also eliminated over the course of the consumption chain which will lead to wastage of food and will also affect the seller's economy. In the material science viewpoint, when the external living tissue of the strawberry fails due to mechanical damage or when there is an internal damage to the fruit because of shear forces [2], compression or tension making it dependent on the texture of the fruit mechanics. This will also be useful in analyzing the fruit quality after harvesting to predict the response at the internal mechanism under various process of handling and also developing the equipment used for mechanical handling such as grading, washing, robot fingers harvesting [3] and packaging [4]. There are two aspects of classifying the strawberry textural mechanics:

- Change in texture due to shelf life and fruit development

- Postharvest conditions and how it has an impact on damaging the fruit 


\section{Related Work}

When observing the fruits development after harvest, researchers concentrated on the firmness changes that were observed. Some researchers also recorded that based on the fruit cultivar, the fruits' firmness varied in [5]. It also depended on fresh-keeping method [6], storage condition [7] and storage time [8]. Contigiani et al. (2018) in [9] noticed that when the strawberry was punctured at $28 \mathrm{~mm} / \mathrm{min}$, it showed a linear increase in the ratio of stress to strain which accounted for about $58 \%$ of the fruit's firmness before it was exposed to mechanical compression [10]. Moreover, washing the strawberries for around 7 minutes along with storage of the fruit in a cold environment, will result in increasing the shelf-life of the fruits and also prevents loss of water and a notable decrease in decay. Similarly in [12] the authors proved how atmosphere packaging impacted the firmness of the fruits. In [11] Zhang et al. observed that as storage time increases, the firmness of the fruit with which it is initially packed decreases. They determined the delay in decrease with the help of puncture tests. In [13] the authors concluded that in order to prolong and maintain firmness of the fruit, coating an edible layer will hold a good effect. Hence about $1 \%$ chitosan is coated on the strawberry which will improve the visco-elastic and gas permeability property, thereby improving the shelf life of the fruits.

\section{Proposed Work}

\subsection{Materials}

In this experiment, we gathere d 'Hongyan' strawberries from a greenhouse located in Australia. About 300 fresh strawberries were plucked in the month of June at the right stage of ripening and taken to the laboratory. Here the fruits' exterior were properly cleaned with fresh water and further at an optimum temperature of $23^{\circ} \mathrm{C}$ they are dried. These strawberry fruits are then stored at a freezing temperature of $5^{\circ} \mathrm{C}$. Within a period of 48 hours, these fruits are to be tested.

\subsection{Physical property Determination}

Initially 246 strawberries were categorized into 4 groups and labelled. On a plastic cylindrical cap that is placed inverted on the table, the fruits are kept such that the stem-blossom is parallel to its surface. The fruit was photographed using a digital camera in all angles, amounting to a total of 360 images. They were transmitted to the laptop and analyzed to determine the minor and major transverse diameter, along with longitudinal height. The minor and major traverse diameters correspond to the orthogonal diameter and maximum diameter on transverse equatorial section. Based on the analysis, it is possible to calculate ' $\mathrm{S}$ ' and 'GMD' which are the surface area and geometric mean diameter. Using an electronic balance with a high accuracy of $0.01 \mathrm{~g}$, the mass of every fruit was weighed and subsequently using an automatic density measuring device, the bulk density of the fruit's tissues were also measured.

$$
\begin{gathered}
S=\pi\left(H D_{1} D_{2}\right)^{2 / 3} \\
\emptyset=\frac{\left(H D_{1} D_{2}\right)^{1 / 3}}{H}
\end{gathered}
$$


Journal of ISMAC (2020)

Vol.02/ No.03

Pages: 166-172

http://irojournals.com/iroismac/

DOI: https://doi.org/10.36548/jismac.2020.3.005

$$
G M D=\left(H D_{1} D_{2}\right)^{1 / 3}
$$

where the minor diameter and the major diameter of the strawberry is represented as $\mathrm{D}_{2}$ and $\mathrm{D}_{1}$ in the transverse equatorial section, $S$ is the fruit's surface area, $\emptyset$ represents the fruit's sphericity, GMD is the geometric mean diameter and $\mathrm{H}$ is the longitudinal height of the strawberry.

\subsection{Fruit Failure Mechanics}



TOP VIEW

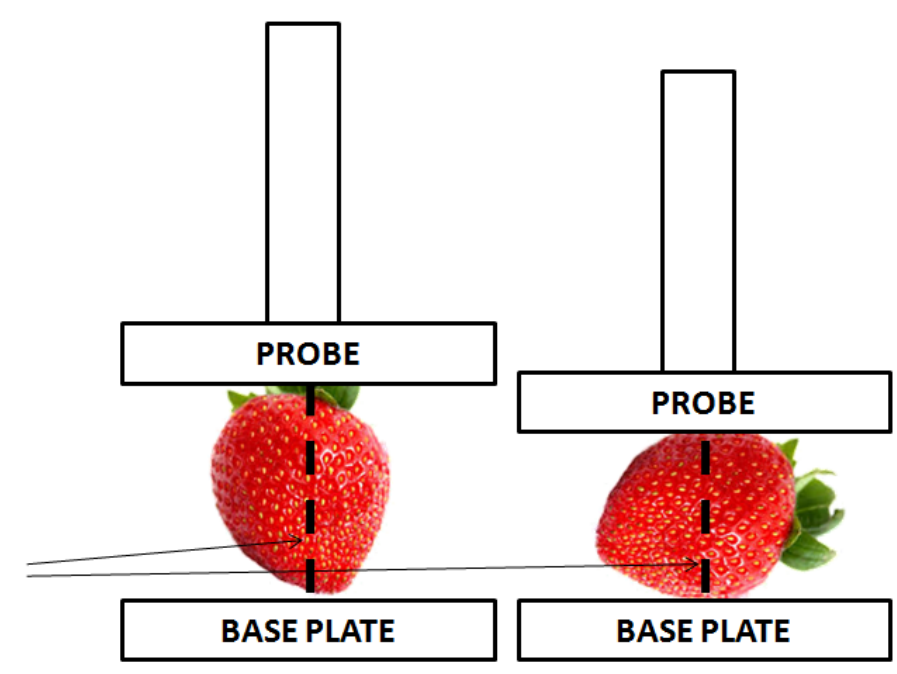

Fig.1. (a) Top View of Strawberry (b) Compression along the Stem Blossom Axis

A complete analysis of the stem blossom axis along the two loading directions with a complete factorial design along the radial and longitudinal equatorial part of the fruit with 8 compressibility levels and 2 compression speeds. Hence the total of 220 strawberries is used to do the loading and the unloading tests. Every fruit under test are compressed to the level of compressibility required by placing between two metal plates. Before executing the test, the device is properly calibrated with a weight of $10 \mathrm{~kg}$. At every point of measurement, the plate with the probe is etched about $10 \mathrm{~mm}$ to the surface of the fruit. From the energy-force deformation curve, the value of absorbed energy, loading slope and peak force are observed. On testing the samples, based on the orientation along the radial axis as well as the stem blossom, the strawberries are sliced into equal halves along the axis. These samples are then allowed to brown by enzymes when they are kept on the table for about 5 hours. Based on the changes in the fruits, the ratio of the water load is taken into account and compared with the value observed before the exposure to air for 5 hours using the following equation:

$$
\eta=\frac{\mathrm{n}_{0}-\mathrm{n}_{0}^{\prime}}{\mathrm{n}_{0}}
$$

where $n_{0}$ represents the mass before loss of water and $n_{0}{ }^{\prime}$ is the mass after water loss. The tissue which is browning is removed from the fruit and the rest of the fruit can be measured as mass $n_{3}$. We have considered that 
Journal of ISMAC (2020)

Vol.02/ No.03

Pages: 166-172

http://irojournals.com/iroismac/

DOI: https://doi.org/10.36548/jismac.2020.3.005

the damaged tissue is due to compression while the other tissues remain unharmed. We have also calculated based on the assumption that there is the same water loss after exposure to air for 5 hours. Hence the mass of the damaged tissue is measured as $\mathrm{n}_{4}$. Moreover $\mathrm{R}$ which represents the percentage of damaged mass is also measured as per the equations given below.

$$
\begin{gathered}
\mathrm{n}_{4}=\mathrm{n}_{1}-\mathrm{n}_{2}-\mathrm{n}_{3}=\mathrm{n}_{1}-\mathrm{n}_{1} \eta-\mathrm{n}_{3} \\
\mathrm{R}=\frac{n_{4}}{n_{1}} \times 100 \%
\end{gathered}
$$

\subsection{Tissue Failure Mechanics}

Every fruit is cut into equal haves such that the strawberries are cut along with the stem-blossom axis as it might help in making rectangular block samples so that it is easy to use pressure between the plates in order to determine if there is difference between the inner and outer tissue of the fruit. With every loading and unloading test, photographs of the fruit were taken. The compressibility level of the fruit was fixed at $40 \%$. The tissues that were prepared is kept at the middle of the plate so that it can be compressed without any deviation and with uniformity. The deformation observed is recorded with the help of a laptop to determine the measure in real-time. Finally other mechanical parameters such as failure Energy, strain, stress and elastic modulus are determined. A total of about 57 tissue samples of strawberries were tested and the observed output values were recorded. The mechanical parameters can be calculated using the following equations:

$$
\begin{gathered}
\sigma_{\mathrm{c}=}=\frac{F_{c \max }}{A_{c}}=\frac{F_{c \max }}{w d} \\
E_{\text {rec }}=\int_{0}^{\Delta L} F d \Delta L \\
E_{c}=\frac{\sigma_{c}}{\varepsilon_{c}} \\
\varepsilon_{c}=\frac{\Delta L}{L}
\end{gathered}
$$

where $\Delta L$ represents change in the sample's difference, $F_{c \text { max }}$ denotes the peak elastic force, $\sigma_{c}$ is the tissue's failure stress and $E_{\text {rec }}$ is failure energy. 
Journal of ISMAC (2020)

Vol.02/ No.03

Pages: 166-172

http://irojournals.com/iroismac/

DOI: https://doi.org/10.36548/jismac.2020.3.005

\section{Results and Discussion}

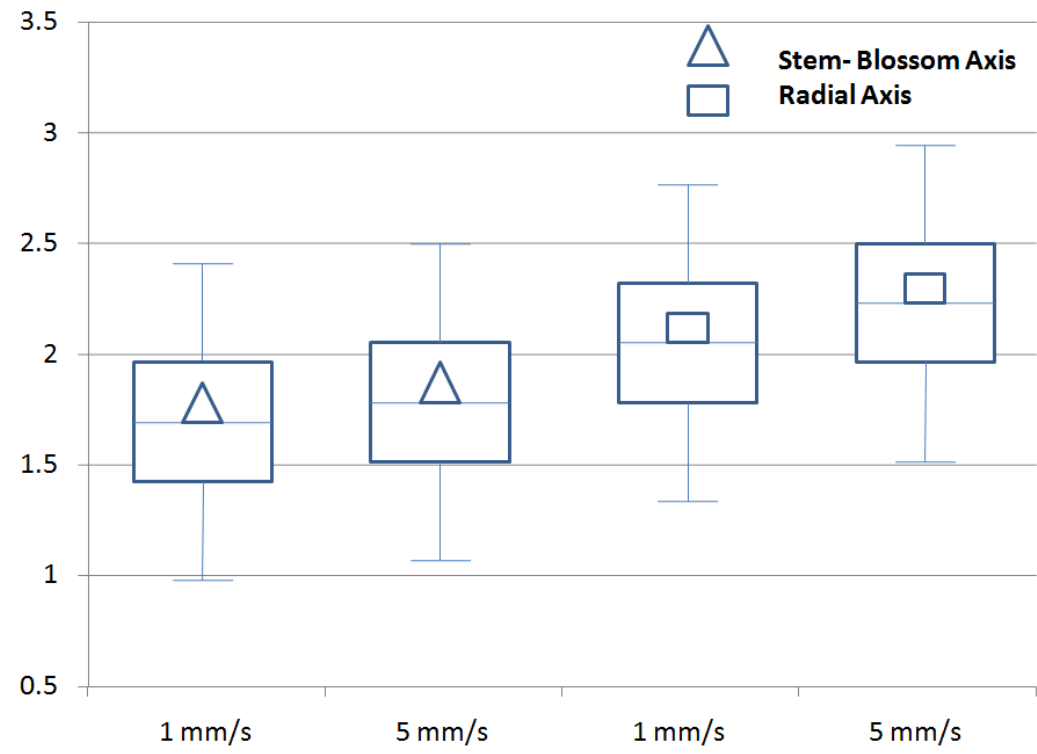

Fig.2. Loading Slope of the fruit under compression

Compression speed and loading direction has an impact on the elastic deformation stage of the fruit, resulting in a loading slope that corresponds to a deformation of about $2.5 \%$. The fruit is compressed along two axis: radial axis and longitudinal axis which result in about $5 \mathrm{~mm} / \mathrm{s}$ of average loading slope which is also found to be greater than that observed for $1 \mathrm{~mm} / \mathrm{s}$. This is mainly due to the effect of theory of momentum which shows that at a rapid speed, the compression peak force is considerably higher. At the same time, it should also be noted that the average loading slope for that of the fruits compressed in the radial axis is found to be higher than that of the stem-blossom axis direction. Hence this will result in the fruit will have better resistance along the radial axis when compared with the stem blossom.

As the final percentage deformation begins to rise rapidly in the beginning with respect to peak force and further increases slowly, it indicates the various deformation endured by the strawberry and preceding inflection point as shown in figure Fig.3. As the contact area between the surface of the fruit and the probe begins to increase with respect to the deformation because of loading, it is observed that the compression position will become convex leading to structural failure of the fruit. Similarly, the compressed cell will also begin to increase leading to the fruit to experience plastic deformation and elastic deformation prior to inflection point. After this point, the fruit will begin to have structural failure deformation. The area of contact between the surface of the fruit and the probe will not increase after the inflection point though the count of compressed cells will increase at a gradual phase with respect to the fruit deformation percentage. 
Journal of ISMAC (2020)

Vol.02/ No.03

Pages: 166-172

http://irojournals.com/iroismac/

DOI: https://doi.org/10.36548/jismac.2020.3.005

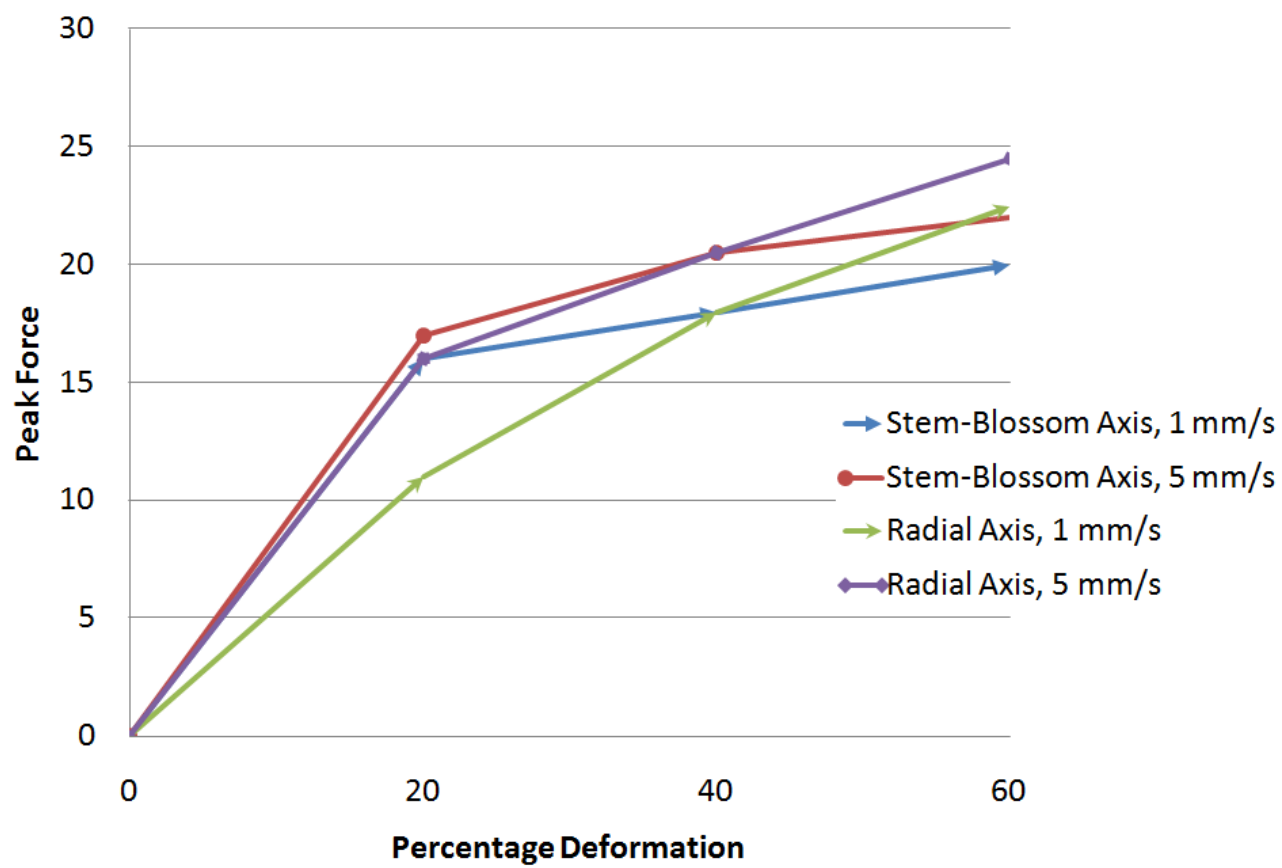

Fig.3. Percentage Deformation Observed for Stem and Radial Axis

\section{Conclusion}

This paper presents an analysis on the strawberries inner tissue and outer external tissue due to external mechanical forces that it is exposed to from the time it is harvested from the farm to the time it reaches the consumer. The fruits are tested under various conditions of temperature and shelf life to determine the optimum ways to ensure that it is preserved for a longer period of time. The average elastic modulus of the inner tissues, failure energy, failure strain and failure stress of the fruit were examined and the values observed were recorded. Based on the analysis performed, it is found that the outer tissue of the strawberries offer higher rate of susceptibility when compared to the internal tissues. The mechanism implemented in this paper can be used to quantitative predict the level of damage that is sustained by the fruits without causing any destruction. Thus these finding will help to further develop more efficient ways in which fruits as well as vegetables can be harvested from the farm with minimal mechanical damage and improve the shelf life of the organic food. This methodology can also be implemented in other similar fruits such as apples, oranges, grapes and plums to numerically estimate the amount of fruits that can be used to be sold in the market and also implement ways to increase their level of susceptibility.

\section{References}

[1] Bovi, G.G., Caleb, O.J., Ilte, K., Rauh, C., Mahajan, P.V., 2018. Impact of modified atmosphere and humidity packaging on the quality, off-odour development and volatiles of 'Elsanta' strawberries. Food Packaging Shelf Life 16, 204-210.

[2] Duarte-Molina, F., Gomez, P.L., Castro, M.A., Alzamora, S.M., 2016. Storage quality of strawberry fruit treated by pulsed light: fungal decay, water loss and mechanical properties. Innovat. Food Sci. Emerg. Technol. 34, 267-274. 
Journal of ISMAC (2020)

Vol.02/ No.03

Pages: 166-172

http://irojournals.com/iroismac/

DOI: https://doi.org/10.36548/jismac.2020.3.005

[3] Kelly, K., Madden, R., Emond, J.P., Do Nascimento Nunes, M.C., 2019. A novel approach to determine the impact level of each step along the supply chain on strawberry quality. Postharvest Biol. Technol. 147, 7888.

[4] La Scalia, G., Aiello, G., Miceli, A., Nasca, A., Alfonzo, A., Settanni, L., 2016. Effect of vibration on the quality of strawberry fruits caused by simulated transport. J. Food Process. Eng. 39 (2), 140-156.

[5] Li, Z., Andrews, J., Wang, Y., 2017a. Mathematical modelling of mechanical damage to tomato fruits. Postharvest Biol. Technol. 126, 50-56

[6] Chandy, A. (2019). RGBD Analysis for Finding the Different Stages of Maturity of Fruits in Farming. Journal of Innovative Image Processing (JIIP), 1(02), 111-121.

[7] Sivaganesan, D. (2019). Design And Development Ai-Enabled Edge Computing For Intelligent-Iot Applications. Journal of trends in Computer Science and Smart technology (TCSST), 1(02), 84-94.

[8] Shakya, S. (2020). Performance Analysis of Wind Turbine Monitoring Mechanism Using Integrated Classification and Optimization Techniques. Journal of Artificial Intelligence, 2(01), 31-41.

[9] Contigiani, E.V., Jaramillo-Sanchez, G., Castro, M.A., Gomez, P.L., Alzamora, S.M., 2018. Postharvest quality of strawberry fruit (Fragaria $x$ ananassa duch Cv. Albion) as affected by Ozone washing: fungal spoilage, mechanical properties, and structure. Food Bioprocess Technol. 11 (9), 1639-1650.

[10] Raj, J. S., \& Ananthi, J. V. (2019). Automation using IoT in greenhouse environment. Journal of Information Technology, 1(01), 38-47.

[11] Zhang, C., Li, W., Zhu, B., Chen, H., Chi, H., Li, L., Qin, Y., Xue, J., 2018. The quality evaluation of postharvest strawberries stored in Nano-Ag packages at refrigeration temperature. Polymers 10, 1-17.

[12] Kelly, K., Madden, R., Emond, J.P., Do Nascimento Nunes, M.C., 2019. A novel approach to determine the impact level of each step along the supply chain on strawberry quality. Postharvest Biol. Technol. 147, 7888

[13] Liang, Z., Xu, L., Baerdemaeker, J., Li, Y., Saeys, W., 2020. Optimisation of a multi-duct cleaning device for rice combine harvesters utilising CFD and experiments. Biosyst. Eng. 190, 25-40.

ISSN: 2582-1369 (online)

Submitted: 22.05 .2020

Accepted: 03.07.2020

Published: 08.07.2020 